sential, fully online can be a good fit if pedagogically sound.

For many institutions and students, a blend of online and in-person study may be the best way forward. Blended learning means that online learning complements, rather than competes with, the traditional campus; supports learners, faculty, and staff where they live (in urban areas at least); and affords creative combinations of individualized and group, and online and in-person learning. This vision of online higher education aligns online and campus development, something that is surely in the long-term interest of most institutions.

DOI: http://dx.doi.org/Io.6oI7/ihe.20I9.97.10935

\section{Maximizing the Civic Mission of Universities}

\section{Ellen Hazelkorn}

Ellen Hazelkorn is emerita professor and director, Higher Education Policy Research Unit, Dublin Institute of Technology, Ireland, and partner, BH Associates, Education Consultants. E-mail: ellen.hazelkorn@dit.ie.

$\mathrm{M}$ ichelle Obama's autobiography, Becoming (2018, p.I47), talks about growing up on the South Side of Chicago, Illinois (US), and the chasm between the University of Chicago and its neighborhood. She writes, "To most everyone I knew growing up, elite meant not for us. Its gray stone buildings almost literally had their backs turned to the streets surrounding the campus... Like many South Siders, my family maintained what was an admittedly dim and limited view of the university, even if my mom had passed a year happily working there."

Michelle's reflections are echoed in a recent United Kingdom survey. According to a 2018 survey by the Civic University Commission, 58 percent of respondents said they were "proud" of their universities. However, 35 percent were unable to name a single thing their local university had done to engage the local community, and 30 percent of lower socioeconomic respondents had never visited a local campus.

\section{Does This Matter?}

Universities have served society well, playing a leading role in nation formation, scientific discovery, and intellectual and public discourse. But nowadays, in the context of widening socioeconomic and regional disparities within countries and competitive economic circumstances globally, there are growing concerns about student performance, learning outcomes, and employment opportunities. The contribution of education and research and their value and impact for national and local objectives are also questioned. There are concerns that pursuit of global reputation and status have come at the expense of social responsibilitiesworries that are reflected by a collapse of trust in public institutions and elites.

Accordingly, in many countries, there is growing public and political demand that universities be more accountable and deliver more public benefit to their cities and regions. Universities are being asked to stretch beyond the traditions of teaching, research, and scholarship, and to reach out beyond their walls, real or metaphorical, in order to connect with their communities and regions in ways that are novel, challenging, and impactful.

These tensions are giving rise to three interrelated issues: public attitudes toward public services, including education; degree of public trust between different sectors of society; and public interest in effective and efficient use of public resources, and the contribution and value to society.

\section{The Engagement Agenda}

"Engagement" now forms a critical part of government and, correspondingly, of higher education agendas. Historically, academic involvement in activities beyond teaching and research or scholarship was described as "service." Over the years, "service" was interpreted primarily as involvement on university committees and/or membership of professional organizations. Today, engagement between universities and society and the economy is a major issue. It is a key component of national policy making, a tool for institutional profiling, and/or an indicator of performance as part of the broader accountability and system steering agendas.

The OECD led an influential project exploring the relationship between higher education and 40 regions and cities, and the drivers and barriers for engagement. The issues were summarized in Higher Education and Regions: Globally Competitive, Locally Engaged. The European Union produced a guide for regional authorities on Connecting Universities to Regional Growth, and is now pursuing a place-based regional development strategy, called smart specialization, for which university research and the vocational education and training system (VET) are key actors. The UNESCO Global Universities Network for Innovation (GUNI) picks up on the idea of the civic university and the need to respond to grand challenges, as set out in the UN's Sustainable Development Goals (SDG), in its report Higher Education in the World: Balancing the Global with the Local.

The European Union has also been developing tools for institutional profiling and ranking to capture categories of knowledge exchange and regional engagement, as well as graduate employment. This began with U-MAP (2005), an 
institutional profiling instrument, and was then applied to U-Multirank (20I4). E3M: European Indicators and Ranking Methodology for University Third Mission (2012) was another EU project. These initiatives are similar to the Carnegie Elective Classification for Communication Engagement (2006). Others include Campus Compact Indicators of Engagement (200I), Talloires Network/Association of Commonwealth Universities Inventory Tool for Higher Education Civic Engagement (2004), initiatives by the Australian Universities Community Engagement Alliance (AUCEA) (2008), and UK National Coordinating Centre for Public Engagement. Global/commercial rankings have also begun to focus on engagement indicators.

\section{Developments in Wales}

Given the significance of higher education for social and economic development, ministries of education in many countries are seeking to steer universities toward a greater degree of civic engagement. Policy instruments employed include national frameworks and priority setting, performance indicators and/or other funding instruments, entrepreneurship education and work-based learning, and evaluation criteria aligned with national priorities.

\section{"Engagement" now forms a critical part of government and, correspondingly, of higher education agendas.}

For example, the Netherlands Strategic Agenda for Higher Education and Research, 2015-2025, identifies knowledge valorization-the creation of economic and social value from knowledge and social benefit-as a key priority. Finland's performance funding model includes indicators related to meeting national and strategic objectives and encouraging cooperation. Ireland's Action Plan for Education, 20I6-20I9, requires institutions to demonstrate how they contribute "to personal development as well as sustainable economic development, innovation, identifying and addressing societal challenges, social cohesion, civic engagement and vibrant cultural activities."

Wales is no different. Traditionally, Welsh higher education has been characterized by a commitment to the people of Wales, with funding from public subscription and lifelong learning opportunities for local people. Today, however, Wales is a net importer of students and net exporter of graduates. In the context of Brexit, forecasts suggest that Wales could become even poorer economically than the rest of the United Kingdom, with a greater gap in educational attainment. Thus, in a determination to steer a distinctive position for itself, the Welsh government has introduced some innovative policy initiatives. Whereas England has embraced a marketized approach to higher education, with escalating tuition fees and growing institutional and regional inequality, the concept of "public good" underpins Welsh public policy. In 20I5, the Well-Being of Future Generations Act made it a statutory requirement for each public body to work toward delivery of seven well-being goals to ensure Wales is prosperous, resilient, healthier, more equal, and composed of cohesive communities with a vibrant culture and Welsh language, and a society that is globally responsible. The new Tertiary Education and Research Commission for Wales (TERCW) will create better coordination across higher and further education and oversee greater civic engagement between institutions and Welsh society.

Against this background, Maximising Universities' Civic Contribution (2018), authored by John Goddard, Ellen Hazelkorn, Stevie Upton, and Tom Boland, made six recommendations:

- Adopting a strategic vision for the postcompulsory sector in Wales

- Including civic engagement as a formal aspect of universities' performance

- Developing regional clusters of institutions as a means of strengthening place-based planning and decision-making between higher education and other parts of Welsh society and economy

- Incentivizing collaboration between universities and other parts of the postcompulsory education sector

- Embedding and widening access and lifelonglearning, including adult education, as intrinsic characteristics and responsibilities of civic mission

- Providing engagement funding for universities contingent on collaboration and alignment with Welsh national and regional priorities.

The intention is to ensure a coherent, integrated approach that does not lead to the siloing of teaching and learning, research and innovation, and engagement and civic mission into three distinct and parallel sets of activities, competing for money, time, and status. Rather, the ambition is to encourage an embedded approach, whereby civic mission is part of the core role and responsibilities of universities, as institutional citizens of and for Wales.

DOI: http://dx.doi.org/ıo.6oI7/ihe.2019.97.10936 